\title{
DAMPAK MEDIA SOSIAL TERHADAP KOMUNIKASI INTERPERSONAL MAHASISWA INSTITUT UMMUL QURO BOGOR
}

\author{
Akhmad Saoqillah, Restu Nada Siti Wardah \\ Institut Ummul Quro Al-Islami Bogor-Indonesia \\ vj.okky@gmail.com
}

Naskah masuk:05-07-2018, direvisi:01-08-2018, diterima:01-09-2018, dipublikasi:18-09-2018

\begin{abstract}
ABSTRAK
Media sosial merupakan media jenis baru yang muncul seiring dengan perkembangnya teknologi informasi belakangan ini. Media sosial mempunyai beragam jenisnya. Misalnya saja ada facebook, instagram, twitter, whatsapp dan lainnya. Media social pada awalnya diciptakan untuk memudahkan manusia dalam berkomunikasi, komunikasi manusia khususnya komunikasi interpersonal jauh lebih mudah dengan adaya media social. Dengan media sosial hubungan komunikasi interpersonal dapat dilakukan hanya dengan gadjet namun hal ini menimbulkan rasa kekhawatiran dari pengguna media social terkait dengan hubungan antar personal. Penelitian ini bertujuan untuk mengkaji dampak media social terhadap komunikasi interpersonal mahasiswa mahasiswa Institut ummul quro al-islami Bogor. Metode penelitian ini menggunakan metode studi literatur. Data yang diperlukan dalam penulisan ini diperoleh melalui buku, jurnal maupun penelitian terdahulu. Hasil penelitian menunjukkan bahwa media social merubah hubungan komunikasi interpersonal khususnya dikalangan mahasiswa, yakni mahasiswa seringkali terlihat sibuk memandang gadjetnya dari pada mengobrol dengan orang disekitarnya.
\end{abstract}

Kata Kunci: Komunikasi, komunikasi interpersonal, Media Sosial

\section{ABSTRACT}

Social media is a new type of media that has emerged along with the development of information technology recently. Social media has various types. For example, there are Facebook, Instagram, Twitter, WhatsApp and others. Social media was originally created to make it easier for humans to communicate, human communication, especially interpersonal communication, is much easier with the presence of social media. With social media, interpersonal communication relationships can be done only with gadgets, but this raises a sense of concern from social media users regarding interpersonal relationships. This study aims to examine the impact of social media on interpersonal communication of students at the Institute of Ummul Quro al-Islam Bogor. This research method using literature study method. The data needed in this writing is obtained through books, journals and previous research. The results showed that social media changed the interpersonal communication relationship, especially among students, that is, students often looked busy looking at their gadgets rather than chatting with people around them.

Keywords: Communication, interpersonal communication, Social Media

\section{PENDAHULUAN}

Masyarakat modern saat ini hampir tidak mungkin tidak terkena paparan media. Disadari atau tidak, media dengan segala kontennya hadir menjadi bagian hidup manusia. 
Seiring dengan perkembangan jaman, kehadiran media makin beragam dan berkembang. Awalnya komunikasi dalam media berjalan hanya searah, dalam arti penikmat media hanya bisa menikmati konten yang disajikan sumber media. Namun seiring perkembangan jaman, orang awam sebagai penikmat media tidak lagi hanya bisa menikmati konten dari media yang terpapar padanya, namun sudah bisa ikut serta mengisi konten di media tersebut.

Muncul dan berkembangnya internet membawa cara komunikasi baru di masyarakat. Media sosial hadir dan merubah paradigma berkomunikasi di masyarakat saat ini. Komunikasi tak terbatas jarak, waktu, ruang. Bisa terjadi dimana saja, kapan saja, tanpa harus tatap muka. Bahkan media sosial mampu meniadakan status sosial, yang sering kali sebagai penghambat komunikasi. Dengan hadirnya Twitter, Facebook, Google+ dan sejenisnya, orang-orang tanpa harus bertemu, bisa saling berinteraksi. Jarak tak lagi menjadi masalah dalam berkomunikasi. Lama waktu terakhir bertemu pun juga tak lagi menjadi masalah. Teman yang telah 20 tahun tak bertemu pun bisa saling menemukan dan menjalin komunikasi lagi. Dan karena kemudahan penggunaannya, hampir bisa dikatakan, siapa saja bisa mengakses dan memanfaatkan media sosial.

Media sosial telah banyak merubah dunia. Memutarbalikkan banyak pemikiran dan teori yang dimiliki. Tingkatan atau level komunikasi khususnya komunikasi interpersonal di kalangan mahasiswa melebur dalam satu wadah yang disebut jejaring sosial/media sosial. Konsekuensi yang muncul pun juga wajib diwaspadai, dalam arti media sosial semakin membuka kesempatan tiap individu yang terlibat di dalamnya untuk bebas mengeluarkan pendapatnya. Akan tetapi kendali diri harusnya juga dimiliki, agar kebebasan yang dimiliki juga tidak melanggar batasan dan tidak menyinggung pihak lain.

Komunikasi interpersonal atau disebut juga dengan komunikasi antar personal atau komunikasi antarpribadi merupakan komunikasi yang dilakukan oleh individu untuk saling bertukar gagasan ataupun pemikiran kepada individu lainnya. Atau dengan kata lain, komunikasi interpersonal adalah salah satu konteks komunikasi dimana setiap individu mengkomunikasikan perasaan, gagasan, emosi, serta informasi lainnya secara tatap muka kepada individu lainnya.

Komunikasi interpersonal dapat dilakukan dalam bentuk verbal maupun nonverbal. Komunikasi interpersonal tidak hanya tentang apa yang dikatakan dan apa yang diterima namun juga tentang bagaimana hal itu dikatakan, bagaimana bahasa tubuh yang digunakan, dan apa ekspresi wajah yang diberikan.

\section{Pengertian Komunikasi Interpersonal}

Berikut adalah beberapa pengertian komunikasi interpersonal menurut para ahli, diantaranya adalah sebagai berikut:

G.R Miller dan M. Steinberg (1975): Komunikasi interpersonal dapat dipandang sebagai komunikasi yang terjadi dalam suatu hubungan interpersonal. (baca: Teori Komunikasi Menurut Para Ahli). Judy C. Pearson, dkk (2011): Komunikasi interpersonal sebagai proses yang menggunakan pesan-pesan untuk mencapai kesamaan makna antarapaling tidak-antara dua orang dalam sebuah situasi yang memungkinkan adanya kesempatan yang sama bagi pembicara dan pendengar.

Dari beberapa pengertian di atas dapat disimpulkan bahwa komunikasi interpersonal adalah komunikasi yang dilakukan dalam suatu hubungan interpersonal antara dua orang 
atau lebih, baik secara verbal maupun nonverbal, dengan tujuan untuk mencapai kesamaan makna.

\section{Sifat Komunikasi Interpersonal}

Menurut Joseph A. DeVito (2013), komunikasi interpersonal memiliki beberapa sifat, yaitu:

Komunikasi interpersonal adalah komunikasi yang melibatkan dua individu atau lebih yang masing-masing saling bergantung. Pada umumnya komunikasi interpersonal adalah komunikasi antara dua orang atau biasa disebut juga dengan komunikasi diadik. Misalnya komunikasi antara seorang anak dan ayah dan lain-lain. Meskipun begitu, komunikasi interpersonal juga merujuk pada komunikasi dalam kelompok kecil seperti misalnya keluarga. Walau dalam keluarga, komunikasi berlangsung dalam bentuk komunikasi diadik seperti ibu kepada anak.

Komunikasi interpersonal adalah secara inheren bersifat relasional. Karena sifatnya yang saling bergantung, komunikasi interpersonal tidak dapat dihindari dan bersifat sangat penting. Komunikasi interpersonal berperan dalam sebuah hubungan yang berdampak pada hubungan dan mengartikan hubungan itu sendiri. Komunikasi yang berlangsung dalam sebuah hubungan adalah bagian dari fungsi hubungan itu sendiri. Oleh karena itu, cara kita berkomunikasi sebagian besar ditentukan oleh jenis hubungan yang ada antara kita dan orang lain. Perlu dipahami pula bahwa cara kita berkomunikasi, cara kita berinteraksi, akan mempengaruhi jenis hubungan yang dibangun. (baca: Komunikasi Pertanian)

\section{Hubungan Interpersonal}

Hubungan interpersonal dapat diartikan sebagai asosiasi antara paling tidak dua orang yang saling bergantung, yang menggunakan beberapa pola interaksi secara konsisten, dan siapa yang menjadi pasangan interaksi dalam sebuah periode waktu. Hubungan interpersonal merupakan hal paling penting dalam dalam komunikasi interpersonal yang efektif.

Jurgen Reusch dan Gregory Bateson (1951) telah mengemukakan bahwa komunikasi mendefinisikan hubungan interpersonal. Pandangan ini telah membuat bergesernya studi komunikasi interpersonal dari isi pesan kepada aspek relasional. Kemudian, Gerarld R. Miller dalam Rakhmat (2001: 119) menyatakan bahwa untuk memahami proses komunikasi interpersonal dituntut adanya pemahaman mengenai hubungan simbiotis antara komunikasi dan perkembangan relasional. Dalam artian, perkembangan relasional dipengaruhi oleh komunikasi hingga pada akhirnya (secara simultan), sifat komunikasi antar partisipan komunikasi dipengaruhi oleh perkembangan relasional.

Dalam sudut pandang psikologi komunikasi, hubungan interpersonal yang baik dapat membuat orang semakin lebih terbuka untuk mengungkapkan dirinya, semakin lebih cermat dalam memberikan persepsi terhadap dirinya dan orang lain, sehingga komunikasi yang berlangsung diantara partisipan komunikasi akan semakin efektif.

\section{Tahapan Hubungan Interpersonal}

Menurut Joseph A. DeVito (2013), hubungan interpersonal dibangun melalui beberapa tahapan, yaitu: 
Pertama kontak. Pada tahapan ini, terdapat beberapa jenis kontak persepsi seperti apa yang kita lihat, apa yang kita dengar, dan lain-lain. Dari tahapan ini kita membentuk sebuah gambaran mental dan fisik seperti gender (Baca: Komunikasi Gender), usia, kepercayaan dan nilai, dan lain-lain. Setelah terjadi persepsi, kemudian dilanjutkan dengana kontak interaksional yang superfisial dan relatif impersonal. Pada tahapan inilah biasanya kita melakukan pertukaran informasi kepada mereka yang terlibat dalam proses komunukasi. Misalnya, "Halo, perkenalkan nama saya Gepeng." Para peneliti berpendapat pada tahapan kontak inilah kita nantinya akan memutuskan apakah kita melanjutkan hubungan atau tidak. (baca: Sistem Komunikasi Interpersonal)

Kedua keakraban. Pada tahapan ini kita berkomitmen pada diri kita sendiri untuk tetap mengenal lebih jauh seseorang dan membentuk sebuah hubungan ketika seseorang tersebut menjadi seorang teman dekat, atau pasangan. Kualitas dan kuantitas pertukaran interpersonal berkembang dan menjadikan kita menjadi lebih sering membicarakan secara rinci tentang hubungan tersebut. (baca: Teori komunikasi Massa).

\section{METODE PENELITIAN}

Pada penelitian ini kami menggunakan jenis/pendekatan penelitian yang berupa Studi Kepustakaan (Library Research). Studi kepustakaan merupakan suatu studi yang digunakan dalam mengeumpulkan informasi dan data dengan bantuan berbagai macam material yang ada di perpustakaan seperti dokumen, buku, majalah, kisah-kisah sejarah, dsb (Mardalis:1999).

Studi kepustakaan juga dapat mempelajari beberbagai buku referensi serta hasil penelitian sebelumnya yang sejenis yang berguna untuk mendapatkan landasan teori mengenai masalah yang akan diteliti (Sarwono:2006). Studi kepustakaan juga berarti teknik pengumpulan data dengan melakukan penelaahan terhadap buku, literatur, catatan, serta berbagai laporan yang berkaitan dengan masalah yang ingin dipecahkan (Nazir:1988). Sedangkan menurut ahli lain studi kepustakaan merupakan kajian teoritis, referensi serta literatur ilmiah lainnya yang berkaitan dengan budaya, nilai dan norma yang berkembang pada situasi sosial yang diteliti (Sugiyono:2012).

\section{Prosedur Penelitian}

Metode penelitian kepustakaan ini digunakan untuk menyusun konsep mengenai Expressive Writing (EW) yang nantinya dapat digunakan sebagai pijakan dalam mengembangkan langkah-langkah praktis sebagai alternatif pendekatan konseling. Adapun langkah-langkah dalam penelitian kepustakaan menurut Kuhlthau (2002) adalah sebagai berikut : 1. Pemilihan topik 2. Eksplorasi informasi 3. Menentukan fokus penelitian 4. Pengumpulan sumber data 5. Persiapan penyajian data 6. Penyusunan laporan

\section{Sumber Data}

Sumber data yang menjadi bahan akan penelitian ini berupa buku, jurnal dan situs internet yang terkait dengan topik yang telah dipilih.

Teknik dan Instrumen Pengumpulan Data

Teknik pengumpulan data dalam penelitian ini adalah dokumentasi, yaitu mencari data mengenai hal-hal atau variabel yang berupa catatan, buku, makalah atau artikel, jurnal 
dan sebagainya (Arikunto, 2010). Instrumen penelitian dalam penelitian ini adalah daftar check-list klasifikasi bahan penelitian, skema/peta penulisan dan format catatan penelitian.

\section{Teknik Analisis Data}

Teknik analisis data yang digunakan dalam penelitian ini adalah metode analisis isi (Content Analysis). Analisis ini digunakan untuk mendapatkan inferensi yang valid dan dapat diteliti ulang berdasarkan konteksnya (Kripendoff, 1993). Dalam analisis ini akan dilakukan proses memilih, membandingkan, menggabungkan dan memilah berbagai pengertian hingga ditemukan yang relevan (Serbaguna, 2005). Untuk menjaga kekelan proses pengkajian dan mencegah serta mengatasi mis - informasi ( Kesalahan pengertian manusiawi yang bisa terjadi karena kekurangan penulis pustaka) maka dilakukan pengecekan antar pustaka dan memperhatikan komentar pembimbing (Sutanto, 2005).

\section{HASIL DAN PEMBAHASAN}

Media sosial memegang peranan yang sangat penting dalam mengekspresikan diri dan mempresentasikan diri. Apapun yang menurut kita penting, akan dikomunikasikan dengan orang lain. Ekspresi inilah yang digunakan untuk membentuk semacam citra atau gambaran di mata orang lain dan cenderung mengarah pada narsisme.

Berbagai hasil penelitian menunjukkan bahwa terlalu banyak mencari informasi melalui internet dapat mengurangi kreativitas, menurunkan konsentrasi dan orisinalitas pikiran.

Media sosial diciptakan untuk interaksi sosial dan memungkinkan terjadinya komunikasi secara lebih cepat, murah, kapanpun dan dimanapun. Di satu sisi, media bermanfaat dalam berkomunikasi dengan orang lain, namun di sisi lain, karena terhubung secara virtual setiap saat dengan status mutakhir dari situs media sosial menyebabkan pengguna media sosial justru tidak berkomunikasi satu sama lain di dunia nyata.

Pengguna media sosial cenderung lebih sibuk berkomunikasi dengan pengguna media sosial lainnya dalam dunia maya bila dibandingkan dengan orang-orang yang berada di sekitarnya, misalnya orang tua atau anak atau kakak atau adik. Manusia seperti terjebak dalam dunia maya.

Hal ini menyebabkan tidak adanya kedekatan dan dapat menurunkan kuantitas dan kualitas komunikasi interpersonal. Adalah benar apabila dikatakan bahwa media sosial merupakan salah satu dari hambatan-hambatan komunikasi dalam konteks komunikasi interpersonal karena melalui media sosial kita tidak dapat membaca komunikasi non verbal sebagai pelengkap dari proses komunikasi interpersonal.

Selain itu, kehadiran media sosial juga berpengaruh terhadap penggunaan bahasa sebagai alat komunikasi, dalam artian isi pesan yang disampaikan secara tertulis melalui media sosial baik formal maupun non formal telah menyebabkan pengguna media sosial melakukan akronimisasi agar dapat sesuai dengan batasan karakter ditentukan oleh platform media sosial. Pesan tertulis dalam media sosial menyebabkan pengguna sosial harus mengintepretasikan tulisan dengan tepat karena apabila tidak maka komunikasi yang efektif melalui media sosial tidak akan dapat tercapai. 


\section{SIMPULAN}

Komunikasi khususnya komunikasi interpersonal dalam media sosial menjadi lebih kompleks. Pasalnya media sosial seakan meleburkan Dua level komunikasi yakni Komunikasi interpersonal dan komunikasi massa. Pada saat orang mengunggah sesuatu, dan terjadi interaksi dengan pihak lain, maka komunikasi interpersonal terjadi, dan disaat yang sama terjadi juga komunikasi massa, sebab apapun yang diunggah bisa langsung dinikmati dan dilihat khalayak banyak.

Dengan kenyataan bahwa apa yang bersifat pribadi bisa menjadi konsumsi publik tersebut, membuat kehadiran media sosial kiranya perlu diperhatikan lagi. Bukan untuk menghentikan perkembangannya, tapi untuk memaksimalkan penggunaannya. Kesadaran diri setiap pengguna penting untuk ditingkatkan, mengingat apa yang diunggah akan bisa mempengaruhi citra diri, dan apa yang diunggah bisa berpengaruh pada hubungan yang terjalin dengan pihak lain.

\section{DAFTAR PUSTAKA}

Alber. (2017). Pengaruh Terpaan Berita Hoax dan Persepsi Masyarakat Tentang Kualitas Pemberitaan Televisi Berita Terhadap Intensitas Menonton Televisi Berita. Jurnal Ilmu Komunikasi Universitas Diponegoro, 1-2.

Aminah. (2018). Peran Media Dalam Komunikasi Politik Jelang Pemilihan Umum Kepala Daerah Tahun 2017 di Kabupaten Aceh Barat. Jurnal Source, 2(3), 1.

Anas, A., \& Farhatulmillah, S. A. (2018). PENGARUH LINGKUNGAN TERHADAP PERKEMBANGAN BAHASA ANAK. Al-Mubin; Islamic Scientific Journal, $1(1), 36-42$.

Batawi, J. W. (2013). Tingkat Kesadaran Politik Pemilih Pemula dalam Pilkada Suatu. UNIERA, 2(Vii), 216-231.

Gunawan, G., \& Aziz, H. (2018). ANALISIS PERKEMBANGAN BAHASA PADA ANAK USIA SMP PEMAIN GAME ONLINE ANDROID BERGENRE BATTLE ROYALE. Al-Mubin; Islamic Scientific Journal, 1(1), 11-21.

Harnowo, T. L. (2017). Dinamika Fake News Atau Hoax Sebagai Sumber Konflik Horisontal Pada Pilkada Provinsi DKI Tahun 2017. Universitas Pertahanan, 2.

Holik, A. (2018, 2019 18). Bahaya Hoax bagi Pemilih Pemula. Retrieved April 8, 2019, from Kumparan: https://kumparan.com/abdul-holik1536333515300/bahaya-hoaxbagi- pemilih-pemula

Junami, U., Eka Prasasti, A. E., Sarwangi, F. F., Amsir, M. D., Syafitri , N., \& Aprilia, N. (2018). Tingkat Pengaruh Hoax Terhadap Masyarakat Jakarta Selatan. (Makalah, Politeknik App Jakarta).

Komariah, K. (2019). Media Sosial dan Budaya Politik Generasi Milineal dalam Pemilu. Aristo, 229.

Mannheim, K. \&. (1955). Essay on Sociology and Social Psychology. Journal of Philosophy, 52 (17), 468-472.

Nasrullah, R. (2015). Media Sosial: Perspektif Komunikasi, Budaya dan sosioteknologi.

Yogyakarta: Simbiosa Rekatama Media.

Prasetyo, Y. (2017). Berita Hoax dan Radikalisme. Kupang: Indonesia.

Priambada, S. (2015). Manfaat penggunaan media sosial pada usaha kecil menengah (UKM). SESINDO, 200.

Struhar. (2014). The Facebook Effect on the News. The Atlantic, 12. 
Suyanto, T. (2017). Persepsi Mahasiswa Prodi PPKn Unesa Terhadap Kemunculan Hoax Di Media Sosial. Prosiding Seminar Nasional Tahunan Fakultas Ilmu Sosial Universitas Negeri Medan 1(1),, 568.

Suyanto, T., Prasetyo, K., Isbandono, P., Zain, I., Purba, I., \& Gamaputra, G. (2018). Persepsi mahasiswa terhadap kemunculan berita bohong di media sosial. Jurnal Civics: Media Kajian Kewarganegaraan, 15(1), 52-61. doi:https://doi.org/10.21831/jc.v15i1.17296

Syamsuadi, A., Hartati, S., Arisandi, D., Murtasidin, B., Elvitaria, L., Trisnawati, L., Febrianita, Y., \& Wulandini, P. (2019). Menjadi Bijak Bagi Pemilih Pemula Berdasarkan Informasi Dari Media Sosial Di Kabupaten Kepulauan Meranti. Jurnal Pengabdian Masyarakat Multidisiplin. 3(1), 27-35.

Undang-Undang Nomor 19 Tahun 2016 Tentang Perubahan Atas Undang-Undang Nomor 28 Tahun 2008 Tentang Informasi Dan Transaksi Elektronik. 